nais, São Paulo, Vol. 653, pp.54 a 68, março de 1990.

BUGARELLI, Waldirio. "Contratos Mercantis". 9ª ed. São Paulo: Atlas, 1997.

CINTRA LEITE, Roberto. "Franchising: na criação de novos negócios". São Paulo: Atlas, 1990. 172p.

COMPARATO, Fábio Konder. "Franquia e concessão de venda no Brasil: da consagração ao repúdio". Revista de Direito Mercantil, In dustrial, Econômico e Financeiro, São Paulo, $\mathrm{n}$ 이, pp.52 a 65, 1975.

DE LENUS, Manuel Medina. "Contratos de co mércio exterior: doctrina y formularios". Madrid: Dykinson, 1998.

GHERSI, Carlos Alberto. "Contratos: civiles y comerciales". Tomo II. $2^{\mathrm{a}}$ ed. Buenos Aires Astrea, 1992.
GOMES, Orlando. "Contratos". 18ª ed. Rio de Janeiro: Forense, 1998.

LOBO, Jorge. "Contrato de 'franchising"'. Rio de Janeiro: Forense, 1997.91p.

MARTINS, Fran. "Contratos e obrigações comerciais". 14ª ed., Rio de Janeiro: Forense, 1997.

GOMES, Orlando. "Contratos". 18ª ed., Rio de Janeiro: Forense, 1998.

MILMAN, Fábio. "Franchising". Porto Alegre: Livraria do Advogado, 1996. 82p.

SIMÃO FILHO, Adalberto. "Franchising: aspectos jurídicos e contratuais". 2ª ed., São Paulo: Atlas, 1997.

STRENGER, Irineu. "Contratos internacionais do comércio". 3a ed., São Paulo: LTr, 1998.

\section{Crise do Direito e Ensino Jurídico*}

\author{
Eduaxda érroeff e Machado Caxion
}

Professor Titular de Direito Constitucional e Diretor da Faculdade de Direito da UFRGS

\section{Introdução}

\begin{tabular}{|} 
SUMÁRIO \\
I. Introdução; \\
II. Crise do Ensino Jurídico; \\
III. Crise do Direito; \\
IV. Investir na Qualificação do Ensino \\
Jurídico; \\
1. Considerações Preliminares; \\
2. Mecanismos de Avaliação dos \\
Cursos Jurídicos; \\
3. Controle da Criação dos Cursos \\
Jurídicos; \\
V. Conclusão.
\end{tabular}

41 o longo de sua história, os cursos jurídicos no Brasil, através da formação de sucessivas gerações de bacharéis, têm alimentado as instituições, em especial as instituições constitucionais. $\mathrm{Da}$ mesma forma, nunca é demais salientar o papel e a importância da criação dos cursos jurídicos para a história republicana do Estado, a primeira Faculdade de Direito tendo sido a Faculdade de Direito da Universidade Federal do Rio Grande do Sul, constituída em 1900 e então denominada Faculdade Livre de Direito de Porto Alegre, sucedida pela instalação da Faculdade de Direito de Pelotas em 1912. Hoje, já temos no Rio Grande do Sul trinta e quatro (34) cursos de direito, oferecidos por vinte (20) instituições de ensino superior, públicas (federais) e privadas.

Com o passar do tempo, os cursos de direito ampliaram significativamente suas 
funções, em correlação aliás com o aumento da complexidade da sociedade contemporânea. Como cursos profissionais que são, destinam-se hoje à formação de bacharéis para o exercício de atividades públicas e privadas as mais diferentes na área jurídica.

Até que ponto os cursos de direito preparam suficientemente seus egressos para o exercício competente das mais diversas atividades jurídicas?

Antes de tudo, cabe lembrar que a situação dos cursos de direito é bastante diversificada, dependendo da região onde se localizam, da condição de serem cursos públicos ou privados e, se privados, da de serem particulares, comunitários, confessionais ou filantrópicos, entre outros elementos. Mas há, em que pesem as diferenças, pontos comuns que merecem exame mais acurado.

Costuma-se falar em uma crise do direito que se traduziria igualmente em uma crise do ensino jurídico. Sem falar, globalmente, na própria crise do modo jurídico de regulação social, trata-se das novas problemáticas e demandas que surgem para a reflexão jurídica neste final de século, assim como também das novas modalidades de solução dos conflitos jurídicos.

A presumida crise do ensino jurídico explicaria em grande parte o surgimento de cursos complementares para bacharéis em direito, alguns melhores, outros piores, com o objetivo de prepararem para concursos públicos e para o exercício da profissão.

Podem os cursos de direito ser suficientemente flexíveis na sua organização curricular, ampliando o elenco de disciplinas eletivas ou facultativas, isto é, daquelas de livre escolha do aluno, de forma a acompanhar as transformações e mudanças na realidade jurídica, mas de forma também a não perderem, por excesso de flexibilidade curricular, sua identidade?

Tende-se, hoje, a reconhecer a importância, nos cursos de direito, do fortalecimento das disciplinas, jurídicas ou não, de base, aquelas que habilitam em grande parte o aluno à reflexão e à criação, como instrumento para enfrentarem-se os novos desafios e problemáticas do direito.

Algumas iniciativas significativas já foram tomadas. A Portaria no 1.886 de 1994 do MEC, que fixa as diretrizes curriculares e o conteúdo mínimo dos cursos de Direito, representa um avanço considerável nesse sentido. Some-se a isso as distintas modalidades de avaliação dos cursos de direito e a correspondente maior exigência de qualificação do ensino ministrado: Avaliação das Condições de Oferta dos Cursos de Direito, de iniciativa da SESu/MEC; Exame Nacional de Cursos, o chamado "Provão", promovido pelo INEP/MEC; Exame de Ordem, de iniciativa da OAB; Ranking das Melhores Faculdades de Direito do País, promovido pela Revista Playboy, entre outras.

Pode-se dizer, sem ser temerário, que há hoje uma preocupação crescente por parte dos responsáveis e administradores com relação à qualidade dos cursos de direito. Muito se encontra ainda por fazer, mas o rumo está fixado. Em especial no Rio Grande do Sul, nossos cursos de direito, nos últimos anos, têm passado por um processo de qualificação crescente; o fortalecimento e a expansão recentes da pós-graduação, com sua capacidade de favorecer a qualificação do ensino de graduação, sendo apenas um dos indicadores positivos.

\section{Crise do Ensino Jurídico}

Já há pelo menos algumas décadas, refere-se a existência de uma crise do ensino jurídico; a afirmação tornando-se inclusive um lugar-comum. Aponta-se assim para o reconhecimento de uma "inadaptação do ensino do direito às condições presentes". Inadequação essa que remete por sua vez a uma própria crise do direito, direito aqui entendido como modo de regulação das relações sociais. Aliás, o caráter e mesmo os resultados das diferentes propostas de reforma do ensino jurídico dependem consideravelmente da pertinência do diagnóstico realizado.

O modelo clássico dos estudos de direito adequava-se antes de tudo a uma sociedade fundada na supremacia de normas genéricas e abstratas, em que o direito, confundido com as regras dos códigos, possuía um papel destacado na organização e na representação social. Neste contexto, o en sino dispensado pelas Faculdades de Direito, intérpretes dos códigos, correspondia significativamente à prática social. Entretanto, essas condições alteraram-se com o tempo, denunciando um cada vez maior descompasso entre as regras dos códigos e a realidade social, sobretudo em sociedades marcadas por profundas desigualdades, como a nossa, o modo jurídico de regulação social encontrando-se em conseqüência afetado. Não só, para indicar apenas alguns elementos desta crise, a intervenção progressiva do Estado nos domínios econômi- co, social e cultural, entre outros, no âmbito de um Estado do Bem-Estar Social, enfraquecendo inclusive o tradicional princípio de legalidade da sociedade liberal, mas principalmente as dificuldades crescentes de o direito resolver a contento conflitos que não são necessariamente ou exclusivamente interindividuais, mas cada vez mais supra-individuais ou intergrupais. Lembre-se contudo a esse propósito que a Constituição de 1988 reconheceu e ampliou o papel dos denominados "novos sujeitos sociais".

A crise do direito, que se traduz em um fenômeno multifacetado, talvez possa ser melhor percebida através da crise do ensino do direito. Assim, as discussões sobre a reforma dos estudos jurídicos serviriam de revelador da crise do direito. Afinal, a crise do direito não é antes de tudo uma crise do conhecimento jurídico? Nesta perspectiva, o ensino do direito não pode constituir-se em lugar privilegiado de resposta à crise do direito?

\section{Crise do Direito}

Mas, quando falamos em crise do direito, de qual crise do direito falamos ou, também, da crise de qual direito falamos? Finalmente, de quais elementos dessa crise do direito falamos? Sem esgotar o exame da matéria, conviria sumariamente chamar a atenção para alguns aspectos da crise do direito, cada um deles podendo ser objeto de amplos desenvolvimentos.

1. descompasso do direito com relação à realidade, problema estrutural;

2. crise do direito como expressão da crise da modernidade e da crise dos paradigmas; 
3. crise da universalidade do direito: superação do etnocentrismo (ver, por exemplo, em matéria de direitos humanos ou de direitos fundamentais, a diversidade das representações do universal);

4. crise do direito estatal e fenômeno do pluralismo jurídico: "a existência, no seio de uma sociedade determinada, de mecanismos jurídicos diferentes aplicandose a situações idênticas" (VANDERLINDEN, Jacques, Le Pluralisme Juridique - Essai de synthèse, in Le Pluralisme Juridique, Editions de l'Université de Bruxelles, Belgique, 1972, p. 19);

5. surgimento de ordens jurídicas paralelas: as "entidades caóticas ingovernáveis" (DE RIVERO, Oswaldo, Les entités chaotiques ingouvernables, in Le Monde Diplomatique, Paris, abril de 1999, p. 3: "As ECI distinguem-se pela impotência de o Estado manter sob seu controle o território nacional e sua população. Amplos setores da economia, das cidades, das províncias e das regiões caem sob o jugo dos novos mestres da guerra, dos narcotraficantes ou das máfias. A legalidade, a ordem pública e os esboços de sociedade civil volatizam-se");

6. crise do modo jurídico de regulação social em face da emergência do modo "midiático" de regulação social; referido;

7. crise do princípio de legalidade, já

8. crise do próprio Estado de Direito, levando ao desequilíbrio entre os poderes;

9. crise da soberania estatal em decorrência do processo de globalização;
10. crise da codificação ou a "era da descodificação";

11. crise do paradigma privatista, também já referida: a percepção de que os conflitos jurídicos não são necessariamente ou exclusivamente interindividuais, mas cada vez mais supra-individuais ou intergrupais; a expansão do "direito social";

12. tentativas de subsunção do tempo do direito, que é um tempo diferido, ao tempo da economia, que é um tempo real ou instantâneo;

13. flexibilização do direito, sobretudo no âmbito do direito do trabalho, na perspectiva de um direito mínimo;

14. crise do próprio ensino jurídico como reflexo da crise do direito, mas alimentando-a e potencializando-a (ver, por exemplo, as dificuldades de adaptação do ensino jurídico às rápidas mudanças do direito);

15. crise do Judiciário: entre outros, o problema do acesso à justiça em face de demandas sociais crescentes.

\section{Investir na Qualificação do \\ Ensino Jurídico}

\section{Considerações Preliminares}

a) dados referentes aos cursos jurídicos:

- Brasil: 320 cursos jurídicos e 43.000 bacharéis (Jornal do Conselho Federal OAB, Junho 1999);

- Rio Grande do Sul: 34 cursos jurídicos (20 instituições de ensino superior) e 3.482 bacharéis (Zero Hora, 06.10.1999); b) consciência da necessidade de implementarem-se instrumentos objetivando uma maior qualificação dos cursos jurídicos: trabalho da Comissão de Especialistas de Ensino de Direito (CEED) da SESu/MEC e da Comissão de Ensino Jurídico do Conselho Federal da OAB e papel da Portaria no 1.886 de 30.12.1994 do MEC.

\section{Mecanismos de Avaliação dos Cursos Jurídicos:}

a) Avaliação Interna por parte das próprias instituições;

b) Avaliação Externa através de.inúmeros mecanismos, entre os quais os seguintes:

- Avaliação das Condições de Oferta dos Cursos de Direito (Plano Global de Avaliação Externa dos Cursos Jurídicos), sob responsabilidade das Comissões de Visita e Avaliação Externa dos Cursos Jurídicos, considerando Corpo Docente, Organização Didático-Pedagógica e InfraEstrutura, de iniciativa da SESu/MEC (Lei $\mathrm{n}^{\circ} 9.131$ de 24.12.1995, art. 3ㅇ, e Decreto no 2.026 de 10.10.1996, arts. 1ㅇ, III, 5o e $\left.6^{\circ}\right)$, talvez o mais completo;

- Exame Nacional de Cursos, o denominado "Provão", promovido pelo INEP/ MEC (Lei no 9.131 de 24.12.1995, art. 3으, e Decreto $\mathrm{n}^{\mathrm{O}} 2.026$ de 10.10.1996, arts. $1^{\mathrm{o}}$, III, 5 e 6 )

- Exame de Ordem, de iniciativa da OAB (Lei no 8.906 de 04.07.1994, art. 8º, IV e $\S 1^{\circ}$ ) , que não abarca a totalidade dos egressos;
- Ranking das Melhores Faculdades de Direito do País, promovido pela Revista Playboy, de caráter mais seletivo.

\section{Controle da Criação dos} Cursos Jurídicos:

a) inicialmente, foi editado o Decre. to $n^{\circ} 2.207$ de 15.04 .1997 , revogado pelo Decreto $\mathrm{n}^{0} 2.306$ de 19.081997 , que o substituiu;

b) nos termos do art. 17 do Décreto $\mathrm{n}^{\mathrm{O}} 2.306$ de 19.08.1997, "a criação e o reconhecimento de cursos jurídicos em instituições de ensino superior, inclusive universidades, dependerá de prévia manifestação do Conselho Federal da Ordem dos Advogados do Brasil".

Tratando-se de universidades ou de centros universitários credenciados, a manifestação favorável do Conselho Federal da Ordem dos Advogados do Brasil dispensa. rá a análise do Conselho Nacional de Educação $\left(\S 4^{\mathfrak{Q}}\right)$. No mesmo caso, a manifestação desfavorável do Conselho $\mathrm{Fe}$ deral da Ordem dos Advogados do Brasil será submetida ao Conselho Nacional de Educação, que deverá emitir parecer conclusivo, dependente ainda de homologação do Ministro de Estado da Educação e do Desporto ( $\S \S 5^{\circ}$ e 6 ) ;

c) impõe-se a utilização da Portaria no 1.886 de 30.12.1994 do MEC, ou de diploma análogo, como critério para a autorização de novos cursos jurídicos.

\section{v. Conclusão}

1. elementos que podem vir a comprometer a almejada qualificação dos cursos jurídicos: 
- persistência de deficiências no ensino fundamental e no ensino médio, pro blema estrutural;

- proposta de cursos seqüenciais, previstos no art. 44, I, da Lei no 9.394 de 20.12.1996 (Lei de Diretrizes e Bases da Educação Nacional);

- proposta de programas de educação à distância, previstos nos arts. 80 e 47, § 3으, da Lei no 9.394 de 20.12.1996 (Lei de Diretrizes e Bases da Educação Nacional): possibilidade de cursos, tanto de graduação como de pós-graduação, nas modalidades semi-presencial, à distância e mesmo on line (ver proposta de Curso de Mestrado da Escola Nacional da Magistratura - ENM, órgão vinculado à Associação dos Magistrados Brasileiros - AMB);

- proposta de mestrados profissionais ou profissionalizantes, regulamentada pela Portaria $\mathrm{n} \times 80$ de 16.12 .1998 do MEC
- proposta de cursos presenciais de especialização, regulamentada pela Resolução n 3 de 05.10.1999 da Câmara de Educação Superior do Conselho Nacional de Educação;

- proposta de aproveitamento dos alunos dos cursos de pós-graduação stricto sensu como professores nos cursos de graduação;

- proposta do Plano Nacional de Educação no sentido de aumentar, em dez anos, a taxa de matrícula no ensino superior, na faixa de idade de 18 a 24 anos, dos atuais em torno de $12 \%$ para $30 \%$.

2. importância da Portaria no 1.886 de 30.12.1994 do MEC, cuja legalidade é hoje questionada em face da superveniência da Lei n 9.394 de 20.12.1996 (Lei de Diretrizes e Bases da Educação Nacional), ou de diploma análogo, como instrumento para alcançar-se uma maior qualificação dos cursos jurídicos.

\section{A Controvérsia sobre os Direitos Humanos}

\author{
Exnst Orugendhat
}

Professor Emérito da Universidade Livre de Berlin

\section{Conferência}

G que são os direitos humanos? Pode se dizer que existem universalmente? Qual o seu significado e o seu conteúdo?

Em primeiro lugar abordaremos qual Hoje faz cinqüenta anos que a Assembléí Geral das Nações Unidas proclamou a Declarafão Universal de Direitos Humanos.

Utma característica desta Declaracão é que alêm dos direitos liberais incluiu igualmente os direitos sócio-económicos.

Eu quero demonstrar porque isto foi correto.

TEXTO DA CONFERENCIA PROFERIDA NO SAL ÃO NOBRE DA FACULDADE DE DIREITO DA UIFRS POR OCASIÁO DO CONGRESSO INTERNACIONAL DE DIREITOS HUMANOS REALIZADO EM COMEMORACAO DOS CEM ANOS DA FACULDADE E DO CINOÜENTENARIO DA DECLARAÇÃO DA ONU. (tradução do Prof. Sérgio Borja ). Porto Alegre, 10 de dezembro de 1998. 9 h a significação de afirmar que existem.

Algumas vezes se fala dos direitos humanos como se fossem direitos naturais; alguns afirmam que nascemos com eles. Mas isto é uma metáfora pois um direito só pode existir se for outorgado. De um lado podese dizer que num Estado os direitos humanos não existem se não estão outorgados pela lei, se não estão contidos na constituição. Por outro lado, se se afirma que são naturais, quer isto significar que estes direitos são anteriores à lei, mas também, nesse caso, têm que ser entendidos como outorgados. Outorgados, nesse caso, por nossa crença moral. Através deste sentido é que se embasaria a sua existência universal. Dizer que dependem da constituição do Estado poderia levar a pensar num relativismo e que os direitos humanos per- 